\title{
Improving the efficiency and environmental safety of gasoline engine operation
}

\author{
E. Magaril \\ Department of Environmental Economics, \\ Ural Federal University, Russia
}

\begin{abstract}
In countries with transition economies a common serious challenge relating to vehicle transport is the increasing shortage of high octane gasoline and its inherent low quality. The aim of this work is to develop a low cost, rapidimplementation method aimed at reducing a vehicle engine's dependency on a gasoline octane rating, the consumption of fuel and the emission of toxic substances in the exhaust gases. The influence of the removal of carbon formation in engines on the improvement of the efficiency of vehicles and the subsequent reduction of their environmental impact was discussed and scientifically substantiated. The technology of coating an engine's working surfaces with ultrafine metal having catalytic activity in redox reactions was developed. A single application of the developed method will provide long-term elimination of carbon deposits on working surfaces. This will reduce the need for high gasoline octane ratings, significantly improve fuel efficiency and also reduce the environmental impact of gasoline engines.
\end{abstract}

Keywords: catalytic layer, carbonization suppression, fuel consumption, environmental and operational characteristics of vehicles.

\section{Introduction}

Currently, the quality of gasoline produced in Russia is far below the standards of developed countries and falls short of the needs of modern vehicles. The main requirement from gasoline is detonation-free combustion in the engine. The fleet of vehicles is growing rapidly and most of those vehicles consume high-octane gasoline. At the same time the increasing shortage of gasoline produced with research octane numbers 95-98 by the Russian oil-refining industry, combined with their inherent low quality, significantly reduces the efficiency and 
environmental safety of vehicle operation and seriously increases dependence on imported oil products [1-3]. One strategic solution to this problem calls for large-scale modernization of the oil industry in Russia. This requires enormous capital investment and is unrealizable in a short time.

The high sulfur content in gasoline produced in Russia precludes the use of the catalytic converters that have been successfully applied to vehicles in developed countries. This leads to increased toxic emissions in exhaust gases, in particular highly carcinogenic polycyclic aromatic hydrocarbons including benzo(a)pyrene.

The use of fuel additives is a quick, low-cost method of improving environmental safety and the efficiency of vehicles $[4,5]$. However, in the absence of any Russian Fuel Quality Standards that compel the petrochemical manufacturers to use additives and the inherent difficulties of immediate gasoline quality control at petrol stations, the search for alternative cost-effective ways to improve the environmental and operating characteristics of vehicles with gasoline engines remains a task of the highest priority. Such methods will be of interest to not only Russia but also other countries including the developed ones.

\section{Background to the method for improving the environmental and operational characteristics of gasoline engines}

The results earlier obtained by the author demonstrate the high efficiency of the developed multifunctional additive for improving the environmental and operational characteristics of motor fuels and cars' performance. The additive is an oil-soluble compound that contains the component, which is catalytically active in redox reactions, and this additive is introduced into the motor fuel in a trace amount [4]. These results led to the hypothesis that it is possible to obtain a significant positive effect through a single introduction of the active component into the engine in an extremely small amount within the fuel.

When selecting the appropriate catalytically active component it is necessary to take into account the fact that carbonization in the engine creates conditions favourable for detonation (an increase of temperature of the combustion chamber) and, in addition, causes surface ignition.

Early burning in the compression stroke, as well as a significant increase in friction after the deposition of carbon on the working surfaces of the engine leads to a substantial increase in energy consumption for the compression. This is resulting in increased fuel consumption with consequent heightened emissions of greenhouse gases $\left(\mathrm{CO}_{2}, \mathrm{CH}_{4}\right.$, etc.). All of these factors lead to a decrease in specific engine power. As a result of surface ignition the heating rate of the working mixture in the compression stroke increases, which further increases the possibility of detonation. The coefficient of the thermal conductivity of the carbon deposits is 1000-2000 times less than that of the metal. Therefore, with an increase in the thickness of the carbon layer the wall temperature rises and heat transfer reduces. 
The increase in the maximum combustion temperature results in a significant increase in the emission of oxides of nitrogen and carbon (CO and $\mathrm{NO}_{\mathrm{x}}$ ) and necessitates an increase in the octane rating of consumed gasoline (up to 10-12 points).

It should also be noted that polycyclic aromatic hydrocarbons, including benzo(a)pyrene, one of the strongest carcinogens, form on the walls as a precursor to carbon deposits, and with the removal of carbonization their emission is almost completely eliminated. Our studies of the influence of carbonization on the operational (requirements for the octane number of gasoline used, the specific fuel consumption) and environmental (the composition of the engine exhaust gases) characteristics of vehicles [4] confirm the prospect of developing methods for the successful elimination of carbonization in engines.

Essentially the prevention of carbonization can be achieved by applying to the working surfaces of the engine a layer of catalytically active metal which is capable of accelerating the rate of reactions of carbon gasification and oxidation:

$$
\begin{gathered}
\mathrm{C}+\mathrm{H}_{2} \mathrm{O} \rightarrow \mathrm{CO}+\mathrm{H}_{2}, \\
\mathrm{C}+\mathrm{CO}_{2} \rightarrow \mathrm{CO}, \\
\mathrm{C}+\mathrm{O}_{2} \rightarrow \mathrm{CO},
\end{gathered}
$$

Based on the analytical studies of the influence of the quality of fuels on the operational and environmental characteristics of vehicles [1-3] and on the catalytic and physicochemical properties of the substances' data [6-8], we have formulated the following requirements to the properties of the metal which could improve the environmental safety and the efficiency of gasoline engines.

- The metal should be an effective catalyst for the oxidation and gasification of carbon deposits. The removal of carbon and the lowering of the temperature in the combustion chamber of a gasoline engine reduce the requirements of a gasoline octane rating. Decreasing the maximum temperature after the carbon deposit removal reduces the thermodynamically possible formation of oxides of nitrogen and carbon and eliminates surface ignition. The amount of carbon deposit on the walls of the combustion chamber is determined by the ratio of the reaction rates of condensation of the aromatic and unsaturated hydrocarbons in the wall's boundary film and the oxidation and gasification of the condensation products (and their precursors) by oxygen, water and carbon dioxide.

- The metal should ensure catalysis of complete oxidation and gasification (with a lack of oxygen) of hydrocarbons and their oxyderivatives, which are formed mostly in the lower temperature area in the wall's boundary film.

- The catalytic properties of the metal must ensure the decomposition and (or) reduction of nitrogen oxide and carbon monoxide oxidation in the reactions:

$$
\begin{gathered}
\mathrm{NO} \rightarrow \mathrm{N}_{2}+\mathrm{O}_{2} \\
\mathrm{NO}+\mathrm{CO} \rightarrow \mathrm{N}_{2}+\mathrm{CO}_{2} \\
\mathrm{CO}+\mathrm{O}_{2} \rightarrow \mathrm{CO}_{2}
\end{gathered}
$$


- The metal must be corrosion-resistant - to ensure the suppression of corrosion in the combustion chamber, refractory - to prevent its removal from the engine, and have good plasticity which will provide a positive impact on the operation of the cylinder-piston group and be introduced in trace amounts to prevent adverse effects on engine operation.

We have also formulated the requirements for the product which is a compound of catalytically active metal, the introduction of which will provide the formation of its layer on the working surfaces of the engine.

- The product should reduce the surface tension at the boundary of the fuel with air to improve its dispersion. This requires a high surface activity of the product.

- The product must maintain the form of a true solution in fuel under all conditions of its use.

- The product must not cause the formation of additional toxic substances in the exhaust gases that are not generated when using fuel without it.

- $\quad$ The product must be able to be synthesized from available and cheap components.

Based on the formulated requirements and screening of the data on the catalytic properties of substances, the author substantiated the composition of an oil-soluble, with high surfactant properties, compound of metal, which is a strong catalyst for the redox reactions. The compound $[\mathrm{RCOO}]_{2} \mathrm{Me}$, (where $\mathrm{R}-$ alkyl radical) was used as the product for generating a catalytically active layer.

When developing the technology to form the catalytically active layer in the engine the author relied on the following:

- The experience of the practical application of highly effective multifunctional additive to gasoline and diesel fuel;

- The results of studies of observed environmental and operational effects' dependence on the parameters of the introduction with gasoline into an engine of the selected oil-soluble compound of the metal.

- Known data relating to the sharp rise in the efficiency of the catalyst when increasing the degree of its dispersion.

The author's unique technology initiates the formation of an ultrafine catalytically active layer of metal under routine engine operating conditions. Uniform thermal deposition on the working surfaces of the engine of the cladding layer of catalytically active metal is facilitated by the decomposition in flame of its oil-soluble compound $[\mathrm{RCOO}]_{2} \mathrm{Me}$. This compound is introduced once into the engine as a finely controlled trace amount in the gasoline and reduces the surface tension of the fuel on the boundary with air, which improves mixture formation in the engine. This provides a high dispersion of the distribution of the metal compound in a fuel-air mixture. Its decomposition in flame in a gasoline engine environment and subsequent deposition of the metal on the working surfaces lead to the formation of an ultrafine catalytic layer.

The uniform distribution of metal is provided by the local conditions of the air-fuel mixture's existence in the engine, namely its high turbulence, temperature, pressure in the combustion process, and significantly lower 
temperatures of the working surfaces in comparison with the melting point of the catalytically active metal. The sizes of working clearance between the cylinder and the piston and the spark plug gap by orders of magnitude exceed the thickness of the catalytic layer, which exclude both a negative effect on the engine's operation and the mechanical removal of the catalyst due to the friction.

\section{Results of applying the catalytic layer in the engine by the developed method}

The influence of the developed method on specific fuel consumption was studied during road tests with the combined driving cycle of UZ-Daewoo's vehicles with Nexia SOHC gasoline engines which had travelled $20000 \mathrm{~km}$ before the test. The decrease in specific fuel consumption, determined by the difference in consumption of the test and control vehicles relative to the test run, after a single-stage treatment of the test vehicle's engine and the formation of the catalyst layer on the working surfaces was $12.3 \%$. The application of the catalyst layer reduced the requirements of the test vehicle's engine for the octane number of gasoline used by 10 points. Investigation into the influence of our method of the catalytically active layer application on carbonization in an engine showed that the catalysis of carbon gasification provides significant cleaning of spark plugs, the valves and cylinder-piston group. Fig. 1 shows photographic evidence of the control and test (coated with a catalytic layer) engines after the testing run.
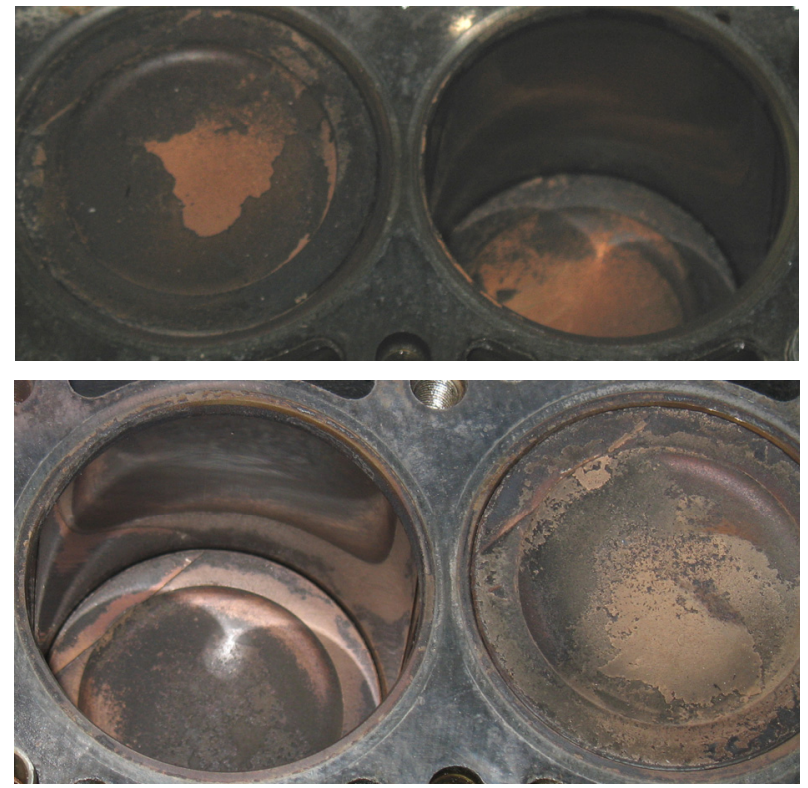

Figure 1: $\quad$ The state of cylinder-piston group of Nexia SOHC engines of UZDaewoo's vehicles after the testing run: a) control vehicle; b) test vehicle coated with the catalytic layer. 
Microscopic examination of samples, prepared from the electrodes of spark plugs of VAZ 2110 vehicle with VAZ 2111 engine (cross-section) was performed by optic microscope Olympus GX-71. After being fixed in special holder the samples were polished in microsection to a mirror surface. The pictures, presented in fig. 2 demonstrate that after the single-stage application of catalytic layer carbon deposits are almost completely eliminated and visual "smoothing" of the electrode surface takes place.

Atomic absorption analysis revealed that engine exhaust gases contained no metal from the catalytically active layer. This fact and the data on the uniform removal of carbon deposits from the engine's working surfaces confirm the very regular formation of the catalytic layer.

The dependence of the amount of polycyclic aromatic hydrocarbons in the exhaust gases of the GAZ-3102 vehicle when idling on the amount of metal introduced into the engine was investigated. The high efficiency of the

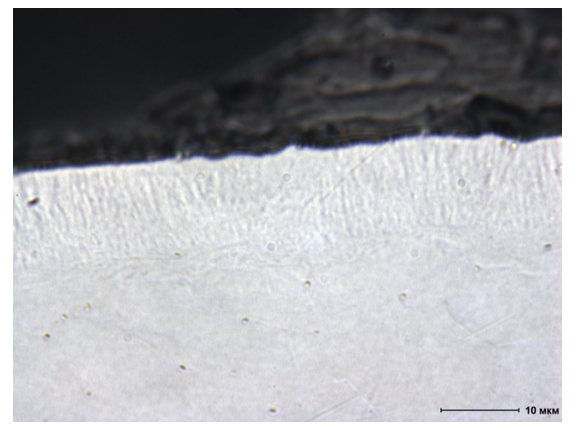

a)

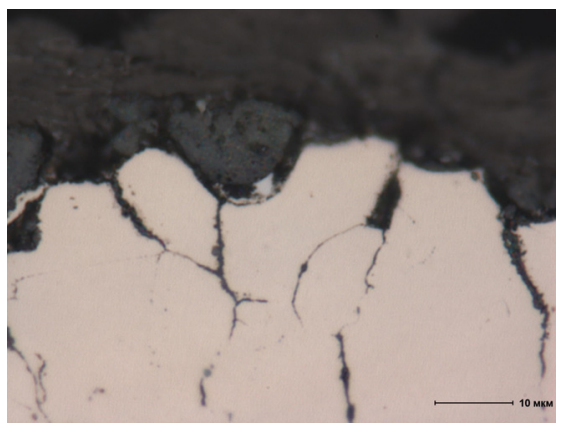

b)

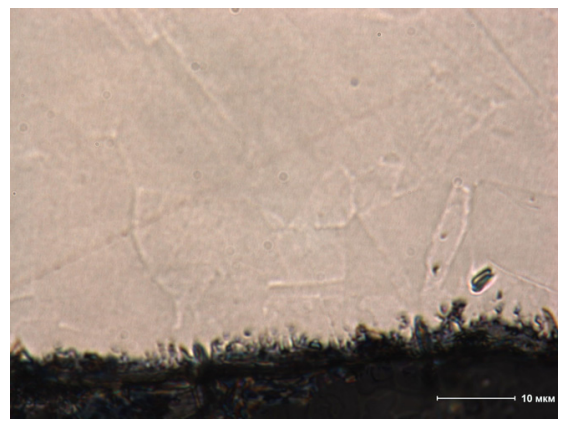

c)

Figure 2: $\quad$ The pictures of the samples prepared from the electrodes of spark plugs in 2000 times zooming taken by optic microscope Olympus GX-71: a) sample 1 - a new spark plug before use; b) sample 2 the used spark plug with the carbon deposit layer; c) sample 3 - the used spark plug after the application of the catalytic layer after daily run. 
developed method (table 1) with respect to the reduction of the emission of polycyclic aromatic hydrocarbons is associated with efficient catalysis of the reaction of gasification by the metal deposited on the wall in an ultra-dispersed state. These results show that the introduction of ultra-low quantities of metal (3$5 \mathrm{mg}$ ) in the $[\mathrm{RCOO}]_{2} \mathrm{Me}$ into the engine with gasoline achieves a reduction of approximately $95 \%$ in the emissions of benzo(a)pyrene and its analogues.

Table 1: $\quad$ The influence of single-stage introduction of $[\mathrm{RCOO}]_{2} \mathrm{Me}$ into the gasoline of a running engine on the content of benzo(a)pyrene and other polycyclic aromatic hydrocarbons in the exhaust gases.

\begin{tabular}{|c|c|c|}
\hline $\begin{array}{c}\text { Amount of the metal } \\
\text { introduced into the } \\
\text { engine, mg }\end{array}$ & $\begin{array}{c}\text { Concentration of } \\
\text { benzo(a)pyrene, } \\
\mathrm{mg} / \mathrm{m}^{3}\end{array}$ & $\begin{array}{c}\text { Total concentration of } \\
\text { polycyclic aromatic } \\
\text { hydrocarbons, lighter than } \\
\text { benzo(a)pyrene, } \mathrm{mg} / \mathrm{m}^{3}\end{array}$ \\
\hline 0 & 0.000230 & 0.00583 \\
\hline 2 & 0.000069 & 0.00181 \\
\hline 3 & 0.000010 & 0.00030 \\
\hline 5 & 0.000009 & 0.00029 \\
\hline 35 & 0.000010 & 0.00030 \\
\hline 90 & 0.000090 & 0.00230 \\
\hline 180 & 0.000180 & 0.00466 \\
\hline
\end{tabular}

*Sensitivity indexes in relation to benzo(a)pyrene are taken equal to 1.

An increase in the amount of metal once introduced into the engine decreases the efficiency of the method, since the degree of dispersion in its deposition on the working surfaces of the engine reduces, which in its turn reduces the catalytic activity. It was found that optimal efficiency in decreasing the emission of polycyclic aromatic hydrocarbons is achieved through very low concentrations of $[\mathrm{RCOO}]_{2} \mathrm{Me}(0.06-0.10 \mathrm{mg} \mathrm{Me} / \mathrm{kg}$ of gasoline).

Testing the influence of the developed method on the environmental characteristics was carried out on a dynamic stand with VAZ-2110 vehicle that before the test had travelled $15000 \mathrm{~km}$ using gasoline with research octane number 92. Results are shown in table 2.

One can assume that to a great extent the catalytic removal of carbon deposit gives the observed effects of reduced emissions of CO (by lowering the maximum operating temperature in the cylinders) and a decrease in specific consumption of gasoline (by eliminating surface ignition and reducing the fuelair mixture heating from the wall). The emissions of $\mathrm{CO}_{2}$ decrease as a result of the decrease in gasoline consumption. The hydrocarbon emission reduces because of catalysis of the reaction of gasification.

It should be noted that with a substantial reduction in $\mathrm{CO}$ emission after the application of the catalytic layer the nitrogen oxide emission remains unchanged. This can be explained by the fact that in tests at $\alpha>1$ the concentration of CO was low and at the same time the nitrogen oxide emission by catalysis of the reaction $\mathrm{CO}+\mathrm{NO} \rightarrow \mathrm{CO}_{2}+\mathrm{N}_{2}$ decreases only with sufficiently high 
concentrations of CO. In tests at $\alpha<1$ after the formation of the catalyst layer in the engine the emissions of nitrogen oxide as a result of the reaction decreased by $27 \%$ at the constant $\mathrm{CO}$ emission.

Table 2: Influence of the developed method on the emission of toxic substances and specific fuel consumption in the combined cycle $($ ECE-15 + EUDC) $(\alpha \geq 1,02)$.

\begin{tabular}{|l|c|c|c|c|c|}
\hline \multirow{2}{*}{ Engine } & \multicolumn{4}{|c|}{ Emisson, g/km } & \multirow{2}{*}{$\begin{array}{c}\text { Gasoline } \\
\text { consumption, } \\
\text { l/100 km }\end{array}$} \\
\cline { 2 - 5 } & $\mathrm{CO}$ & $\mathrm{CH}$ & $\mathrm{NO}_{\mathrm{x}}$ & $\mathrm{CO}_{2}$ & 9.62 \\
\hline Before treatment & 3.3 & 1.6 & 2.0 & 147.1 & \\
\hline $\begin{array}{l}\text { After the } \\
\text { catalytic layer } \\
\text { application }\end{array}$ & 2.3 & 1.3 & 2.0 & 138.4 & 8.95 \\
\hline Change, \% & -30.3 & -18.8 & - & -5.9 & -7.0 \\
\hline
\end{tabular}

Thus, the investigations and tests carried out confirm that coating the working surfaces of gasoline engines with a layer of metal that is catalytically active in the reactions of gasification reduces emissions of polycyclic aromatic hydrocarbons, including benzo(a)pyrene by 95\%, and also eliminates carbon deposits. As a result of carbon deposit removal and appropriate mitigation of temperature conditions in the engine the dependency on a gasoline octane rating reduces by up to 10 points and the specific consumption of fuel decreases by 7$12 \%$, which leads to a reduction in the emission of greenhouse gases and toxic gaseous substances. The positive effects of the method are retained for a minimum of twelve months after the application of the catalytic layer in the engine.

\section{Conclusion}

Compulsory application of the catalytic layer in the manufacturing of vehicles at car plants, and for used cars - annually at service stations, without an increase in the overall cost of the engine will significantly increase the efficiency and environmental safety of the vehicles and in a cost-effective manner will resolve the problem of the shortage of high-octane gasoline.

The practical implementation of the developed method is of great socioeconomic importance because of the significant reduction to urban environment degradation, increased cost-effectiveness, both for the manufacturers of motor fuels, due to lower requirements for gasoline octane ratings, which significantly reduces the cost of production, and for the consumer through the reduction of specific fuel consumption. 


\section{References}

[1] Magaril, E.R. Influence of the quality of engine fuels on the operation and environmental characteristics of vehicles: monograph, [in Russian], KDU: Moscow, 2008.

[2] Magaril, E.R., Magaril R.Z. Motor fuels [in Russian], second edition, KDU: Moscow, 2010.

[3] Magaril, E., Magaril, R. Motor fuels: the problem of energy efficiency and environmental safety: monograph, [in Russian], LAP LAMBERT Academic Publishing GmbH and Co: Saarbrücken, Germany, 2012.

[4] Magaril, E., Improving car environmental and operational characteristics using a multifunctional fuel additive. Proc. of 19th Int. Conf. on Modelling, Monitoring and Management of Air Pollution, eds. C.A. Brebbia and J.W.S. Longhurst, WIT Press: Southampton, pp. 373-384, 2011.

[5] Bozek, F., Dvorak, J., Mares, J., Malachova, H., Reduction of Emissions of Nitrogen Oxides from Traffic. World Academy of science engineering and technology, 58, pp. 145-150, 2011.

[6] Roiter, V. A. (main editor), Catalytic properties of substances, [in Russian], Naukova dumka: Kiev, 1968.

[7] Thomas, C., Catalytic processes and proven catalysts, Academic Press: London and New York, 1970.

[8] Germain, J. E., Catalytic Conversion of Hydrocarbons, Academic Press: London and New York, 1969. 